\title{
What Runs in the Family? Relations Between Parent-Child Characteristics in Cases with Autism and Typical Development
}

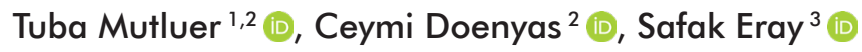 \\ ${ }^{1}$ Koç University School of Medicine, Department of Psychiatry, Division of Child and Adolescent Psychiatry, Istanbul, Turkey \\ ${ }^{2}$ Koç University Research Center for Translational Medicine, Istanbul, Turkey \\ ${ }^{3}$ Uludag University, Medical Faculty, Department of Child and Adolescent Psychiatry, Bursa, Turkey
}

\begin{abstract}
Objective: Though twin studies have mainly been the focus of genetic studies in autism spectrum disorder (ASD), trait inheritance studies between parents and children are also valuable to guide genetic investigations. Therefore, we aimed to investigate the relationship between parent psychological and behavioral profiles and child problem behaviors in families with children with ASD and children with typical development (TD). In the ASD group, we further investigated specific associations between psychological symptoms of parents and ASDspecific behaviors of children.

Methods: Childhood Behavior Checklist (CBCL) and Symptom Checklist 90 (SCL-90R) were used to measure behavior problems of children and psychological problems in parents. These scales were used with children with ASD and their mothers $(n=64)$ and TD children and their mothers $(n=53)$. Additionally, for children with ASD only, the ASD diagnosis was confirmed with semi-structured interviews using Childhood Autism Rating Scale (CARS) and behavioral domains were measured with the help of Aberrant Behavior Checklist (ABC).

Results: Both the CBCL and the SCL-90R scores were higher in the ASD group compared to the TD group. In the ASD group, beyond demographic variables, mother obsessive-compulsive symptoms significantly predicted child stereotypic behaviors and inappropriate speech, which includes repetitive speech and repeating words/phrases. Mother depression symptoms significantly predicted inappropriate speech in children with ASD beyond demographic variables.

Conclusion: Our findings point to obsessive-compulsive traits as potential targets of investigation in the quest to unravel the genetic profile of ASD. Parent obsessive-compulsive symptoms may have a hereditary component that can constitute a risk factor for ASD or for the severity of specific behavioral domains of ASD in their children.

Keywords: Autism Spectrum Disorder, Child Behaviors, Family, Inheritance, Obsessive-Compulsive, Parent-Child, Parent Symptoms
\end{abstract}

\section{INTRODUCTION}

Autism spectrum disorder (ASD) is a neurodevelopmental disorder presenting with deficits in social interaction and communication, and with repetitive behaviors and restrictive interests (1). Though twin studies indicate a strong genetic component in ASD and the estimated ASD heritability is between 64-91\%, the common variants of the genetic composition of ASD are still unknown (2). Additionally, strong evidence was recently provided for the contribution to ASD of epistasis or gene-gene interaction (3), suggesting that

\section{Corresponding Author: Ceymi Doenyas}

Koc University Research Center for Translational Medicine, Istanbul. E-mail: ceymidoenyas@alumni.princeton.edu

Citation: Mutluer T, Doenyas C, Eray S. What Runs in the Family? Relations Between Parent-Child Characteristics in Cases with Autism and Typical Development. Psychiatry and Behavioral Sciences 2020; 10(3):103-109.

Doi: 10.5455/PBS.20200408111354 unraveling the genetic makeup of ASD may be more complicated than previously believed; not being limited to single genes but also including their interactions. Though there is genetic heterogeneity in ASD, the associated genes seem to converge on certain molecular pathways such as protein synthesis and degradation, chromatin remodeling, and intracellular signaling, which are suggested to be related to changes in social and cognitive behaviors (4). So, genetic studies seem to imply that the commonly influenced pathways in ASD may translate to behavioral differences. Such an implication points to inheritance studies as valuable contributions to inform this field, alongside the more popular twin studies. With this purpose, the present study looked at the relationships between parent and child traits in ASD and compared these relationships to those in families with neurotypical development. We believe that such a study can assist genetic studies by providing behavioral and symptomatologic inheritance information in ASD 
as different from neurotypical families, which can highlight potential areas of focus for investigating the commonalities in the genetics of ASD.

The relatives of individuals with ASD are repeatedly reported to exhibit certain language, personality, and social-behavioral characteristics that resemble ASD symptoms but are expressed in a milder form (5). Broad autism phenotype (BAP) is described as impairments in cognitive, social, communicative, behavioral, and personality domains of the relatives of the children with ASD (6). Also, the relatives in the families with multiple-incidence ASD have higher rates of social and communication deficits and stereotyped behaviors. The BAP findings for parents of children with ASD have been shown to be manifest in grandparents, aunts, and uncles of children with ASD as well, suggesting the expression of genetic liability for ASD (7). Such BAP characteristics have previously been investigated with the hopes to provide a complementary approach to finding the genes related with ASD, and individuals with ASD and their parents with BAP were found to differ from controls and parents without BAP in measures of social cognition, but not in measures of executive function and central coherence (5). Though such social cognition deficits are expected given the social nature of impairments in ASD, we believe that looking at other, more extensive clinical symptoms will be informative in revealing specific behavior or symptom groups that are more likely to be inherited in ASD than in neurotypical development.

Insistence on sameness in children with ASD was shown to be positively correlated with obsessive-compulsive behaviors in parents (8). Children with ASD who have more repetitive behaviors were significantly more likely to have one or more parents with obsessive-compulsive disorder (OCD) or traits compared to children with ASD with less repetitive behaviors and OCD disorder or trait in parents was significantly more likely if the child with ASD had a high occurrence of repetitive behaviors (9). Also, social anxiety and depression were shown to be higher in relatives in families with multiple-incidence ASD (10). OCD and ASD are both highly heritable disorders that share genetic risk factors. The genetic association between OCD and ASD has been investigated and this combined genome-wide association study (GWAS) revealed a significant polygenic component of ASD, predicting $0.11 \%$ of the phenotypic variance in an independent OCD data set (11). More broadly, children of parents with a neurodevelopmental or a neuropsychiatric disorder were found to display more restricted and repetitive behaviors than children of parents without such disorders (12).

Though these few studies investigated the inheritance of symptoms in families with and without ASD, they have looked at predictable domains for ASD that are restricted to a single area, such as social cognition, repetitive behaviors, and insistence on sameness. Taking these studies one step further, we set out to look at a wider range of symptoms and behaviors in parents and children and their relationships, and how these relationships differ in families with children with ASD and typically developing (TD) children.

The present study measured child behaviors and characteristics comprehensively using the Child Behavior Checklist that informs about withdrawal; somatic complaints; and anxious/depressed, delinquent, and aggressive behavior of children, for both children with ASD and TD children. We measured parent psychological problems and symptoms using Symptom Checklist 90 in parents of both groups. In addition, we used the Aberrant Behavior Checklist for children with ASD to get a clearer understanding of how different behaviors associated with ASD relate to the psychological symptoms of their parents.

Given the previous findings, we expected obsessivecompulsive behaviors of parents to relate to stereotypic behaviors in children with ASD, but given the lack of evidence otherwise, we approached the relations between other parent-child characteristics in an exploratory manner.

\section{METHODS}

\section{Participants}

Participants comprised 64 children with a clinical ASD diagnosis and their mothers and 53 TD children and their mothers (Table 1). Children with ASD were recruited from the patients followed by Istanbul University Medical Faculty Child and Adolescent Psychiatry outpatient clinic (14 cases) and Hamit Ibrahimiye Education Center for Children with Autism (50 cases). The control group was formed from students attending a school located in the epidemiological catchment area of the study center (Cenab Sehabettin Elementary School), which matched the children with ASD in terms of age and gender $(53$ children, 13 females). Exclusion criteria for both groups included having a diagnosis of a genetic (e.g., Fragile $\mathrm{X}$ syndrome), neurological (e.g., epilepsy), metabolic, respiratory (e.g., chronic asthma, bronchiolitis) or chronic infectious disorder (e.g., tuberculosis, pneumonia) as diagnosed by pediatricians and listed in the medical 
reports of patients and reported by the mothers; having a history of severe head injury or organic brain damage; and having used pharmacological agents such as Risperidone or Methylphenidate during the previous month. All mothers had at least an elementary school education (Table 1). Approval was received from the Ethical Committee of the Medical Faculty of Istanbul University (Number: 2012/1063-1149, Date: 12.07.2012), and permissions were acquired from relevant authorities. Written and oral informed consent was obtained from all mothers, and their children when appropriate.

Table 1. Participant information for ASD group and TD group

\begin{tabular}{|c|c|c|c|c|c|c|c|c|}
\hline & \multicolumn{4}{|c|}{ ASD Group $(n=64)$} & \multicolumn{4}{|c|}{ Control Group ( $n=53$ ) } \\
\hline & $M$ & $S D$ & Min & Max & $M$ & $S D$ & Min & Max \\
\hline Child age & 11.66 & 3.82 & 6 & 18 & 11.75 & .85 & 10 & 13 \\
\hline Mother age & 38.25 & 6.27 & 25 & 52 & 40.08 & 4.59 & 31 & 48 \\
\hline \multirow[t]{2}{*}{$\begin{array}{l}\text { Number of } \\
\text { children in family }\end{array}$} & 2.14 & 1.01 & 1 & 5 & 1.91 & .56 & 1 & 3 \\
\hline & $n$ & \multicolumn{3}{|c|}{$\%$} & $n$ & \multicolumn{3}{|c|}{$\%$} \\
\hline Child gender & 53 male & \multicolumn{3}{|c|}{$82.8 \%$} & 40 male & \multicolumn{3}{|c|}{$75.5 \%$} \\
\hline $\begin{array}{l}\text { Mother } \\
\text { employment } \\
\text { status }\end{array}$ & $\begin{array}{c}50 \\
\text { unemp. }\end{array}$ & \multicolumn{3}{|c|}{$78.1 \%$} & $\begin{array}{c}24 \\
\text { unemp. }\end{array}$ & \multicolumn{3}{|c|}{$45.3 \%$} \\
\hline \multicolumn{9}{|l|}{$\begin{array}{l}\text { Mother's } \\
\text { Education }\end{array}$} \\
\hline $\begin{array}{l}\text { Elementary } \\
\text { School Graduate }\end{array}$ & 31 & \multicolumn{3}{|c|}{$48 \%$} & 57 & \multicolumn{3}{|c|}{$49 \%$} \\
\hline $\begin{array}{l}\text { Middle School } \\
\text { Graduate }\end{array}$ & 15 & \multicolumn{3}{|c|}{$23 \%$} & 19 & \multicolumn{3}{|c|}{$8 \%$} \\
\hline $\begin{array}{l}\text { High School } \\
\text { Graduate }\end{array}$ & 8 & \multicolumn{3}{|c|}{$13 \%$} & 22 & \multicolumn{3}{|c|}{$26 \%$} \\
\hline $\begin{array}{l}\text { University } \\
\text { Graduate }\end{array}$ & 10 & \multicolumn{3}{|c|}{$16 \%$} & 19 & \multicolumn{3}{|c|}{$17 \%$} \\
\hline $\begin{array}{l}\text { Consanguineous } \\
\text { marriage }\end{array}$ & 14 & \multicolumn{3}{|c|}{$22 \%$} & - & & & \\
\hline C-section births & 29 & \multicolumn{3}{|c|}{$46 \%$} & 32 & \multicolumn{3}{|c|}{$60 \%$} \\
\hline $\begin{array}{l}\text { Problematic } \\
\text { pregnancy period }\end{array}$ & 21 & \multicolumn{3}{|c|}{$33.3 \%$} & 4 & \multicolumn{3}{|c|}{$8 \%$} \\
\hline
\end{tabular}

M: Mean; n: Number; SD: Standard Deviation; \%: Percentage; Min: Minimum; Max: Maximum; Unemp: Unemployed.

\section{Measures}

For all children. Demographic forms filled by mothers indicated child age, maternal age, and maternal education. Childhood Behavior Checklist (CBCL) was used to measure children's behavioral and emotional problems, which are categorized into withdrawn, delinquent, aggressive behaviors; social, attention, thought problems; somatic complaints; and being anxious/depressed. This scale was originally created by Achenbach (13). In this Turkish sample, the Turkish standardized version of this scale was used (14).
For children with ASD only. Aberrant Behavior Checklist $(A B C)$ is a list scored by parents that measure irritability, social withdrawal, stereotypic behaviors, hyperactivity/ noncompliance, and inappropriate speech in children with ASD. This scale was created by Aman and colleagues [15] and its Turkish version that has been approved for validity and reliability by Karabekiroglu and Aman was used in this sample and was filled by the mothers (16).

Childhood Autism Rating Scale (CARS) is a behavior observation scale used by trained observers to rate the symptoms of children with ASD to yield a total score for ASD severity. The original scale's Turkish version was used in this sample as a diagnostic tool, which was approved for validity and reliability $(17,18)$. CARS was administered by the clinical researchers as a semistructured interview.

For all mothers. Symptom Checklist 90 revised (SCL-90R) is a self-report scale measuring parent psychological symptoms under the categories of somatization, obsessivecompulsive, interpersonal sensitivity, depression, anxiety, phobic anxiety, hostility, paranoid ideation, and psychoticism (19). Higher scores in this scale indicate higher problems in these domains, for instance, having higher scores in interpersonal sensitivity does not suggest better interpersonal sensitivity but more problems in that area. The Turkish version of this scale that shows acceptable validity and reliability for the Turkish population was filled by mothers of both groups of children (20).

\section{Analysis Plan}

IBM SPSS (Version 27.0, Armonk, NY) was used to analyze our quantitative data. We used the Smirnov Test for normality because of our relatively small sample size. Initially, to compare the demographics between groups, an independent-samples t-test was conducted. For the analyses, first, Pearson correlations between mother psychological symptoms and child behaviors and characteristics were investigated and compared for two groups. Second, Pearson correlations between ABC scores of children with ASD and psychological symptoms of mothers were examined. The significantly correlated variables were then put into a hierarchical regression analysis to see if these predictions held over and above socio-demographic variables.

\section{RESULTS}

Comparison of demographic information of two groups revealed no significant differences in terms of child age, maternal age, mother education, and the number of 
children in the family (Table 1). Significant differences were found in mother employment status, where more parents of children with ASD were unemployed and in problematic pregnancies, where more mothers of children with ASD experienced problems in their pregnancy (Table 1).

The results revealed significantly higher $\mathrm{CBCL}$ and SCL90R scores for the ASD group compared to the control group $(t(108)=6.49, p<.001$ and $t(115)=7.33, p<.001$, respectively). The mean CBCL score in the ASD group was $62.84 \pm 9.9$ and the mean score was $48.96 \pm 12.5$ in the control group. The mean SCL-90R score was $11.65 \pm 6.2$ in the ASD mothers group and it was $4.58 \pm 3.7$ in the control mothers group. In both measures, higher scores indicate more problems. The CARS scores of participants with ASD ranged between 24.00 and $52.50(M=36.97 \pm$ 6.9 ), indicating that all participants in the ASD group were on the spectrum, ranging from mildly to severely autistic.

\section{Relations Between Parent-Child Characteristics}

When the relations between mother symptoms and child behaviors were investigated, for the ASD group (Table 2), a lot of correlations emerged. Yet, when HolmBonferroni correction was applied, only the relations between maternal depression and child aggressive behavior, mother obsession and child anxious-depressed behavior, and mother obsession and child aggressive behavior scores remained significant in the ASD group.

Table 2. Correlations between parent psychological symptoms and child behavioral problems in ASD group

\begin{tabular}{|c|c|c|c|c|c|c|c|c|}
\hline $\begin{array}{l}\text { Child } \\
\text { Behavior } \\
\text { Problems } \\
\text { Parent } \\
\text { Symptoms }\end{array}$ & Withdrawn & $\begin{array}{c}\text { Somatic } \\
\text { complaints }\end{array}$ & $\begin{array}{l}\text { Anxious/ } \\
\text { depressed }\end{array}$ & $\begin{array}{c}\text { Social } \\
\text { problems }\end{array}$ & $\begin{array}{l}\text { Thought } \\
\text { problems }\end{array}$ & $\begin{array}{l}\text { Attention } \\
\text { problems }\end{array}$ & $\begin{array}{c}\text { Delinquent } \\
\text { behavior }\end{array}$ & $\begin{array}{c}\text { Aggressive } \\
\text { behavior }\end{array}$ \\
\hline Somatization & .23 & .26 & $.42 * *$ & .19 & .12 & .15 & $.29 *$ & $.42^{* *}$ \\
\hline Anxiety & .19 & .18 & $.29 *$ & .23 & .20 & .14 & .25 & $.32 *$ \\
\hline Obsessive-compulsive & $.39 * *$ & $.27^{*}$ & $.48^{* * *}$ & $44 * * *$ & $.27^{*}$ & $.35^{* *}$ & $.32 *$ & $.48 * * *$ \\
\hline Depression & $.33^{*}$ & $.27^{*}$ & $.43^{* *}$ & $.38 * *$ & $.30 *$ & $.34 *$ & $.41 * *$ & $.50 * * *$ \\
\hline Interpersonal sensitivity & .26 & .18 & $.33^{*}$ & $.29 *$ & $.28^{*}$ & .26 & .23 & $.33^{*}$ \\
\hline Psychoticism & .26 & $.33^{*}$ & $.31 *$ & .26 & $.28^{*}$ & .20 & .25 & $.28^{*}$ \\
\hline Paranoid ideation & $.28 *$ & $.32 *$ & $.36 * *$ & $.31^{*}$ & $.34^{* *}$ & .25 & .23 & $.40 * *$ \\
\hline Hostility & $.32 *$ & $.27^{*}$ & $.41 * *$ & $.30 *$ & .21 & .16 & $.28^{*}$ & $.31^{*}$ \\
\hline Phobic anxiety & $.28^{*}$ & .19 & $.30 *$ & .22 & .22 & .15 & .17 & .22 \\
\hline
\end{tabular}

${ }^{*} p<.05, * * p<.01,{ }^{* * *} p<.001$. Bolded values indicate significance at the .05 level, and italicized values indicate marginal significance at the .10 level after Holm-Bonferroni correction.

When these relations were examined for the TD group, the relations in Table 3 were obtained. After HolmBonferroni correction, the only significant relation ( $p$ $<0.05)$ was between mother psychoticism and child delinquent behavior.
These analyses showed that mother psychological problems were associated with child behavior problems to a greater degree in the ASD group compared to the control group, and both mother psychological problems and child behavior problems were higher in the ASD

Table 3. Correlations between parent psychological symptoms and child behavioral problems in TD group

\begin{tabular}{|c|c|c|c|c|c|c|c|c|}
\hline $\begin{array}{l}\text { Child } \\
\text { Behavior } \\
\text { Problems } \\
\text { Parent } \\
\text { Symptoms }\end{array}$ & Withdrawn & $\begin{array}{c}\text { Somatic } \\
\text { complaints }\end{array}$ & $\begin{array}{l}\text { Anxious/ } \\
\text { depressed }\end{array}$ & $\begin{array}{c}\text { Social } \\
\text { problems }\end{array}$ & $\begin{array}{l}\text { Thought } \\
\text { problems }\end{array}$ & $\begin{array}{l}\text { Attention } \\
\text { problems }\end{array}$ & $\begin{array}{c}\text { Delinquent } \\
\text { behavior }\end{array}$ & $\begin{array}{l}\text { Aggressive } \\
\text { behavior }\end{array}$ \\
\hline Somatization & .12 & .18 & .10 & .26 & .15 & .17 & .22 & .09 \\
\hline Anxiety & .14 & .13 & .14 & .11 & .13 & .12 & $.38 * *$ & .16 \\
\hline Obsessive-compulsive & .09 & .04 & .19 & .17 & .16 & $.29 *$ & $.37 * *$ & .13 \\
\hline Depression & .11 & .04 & .16 & .16 & .15 & .22 & $.30 *$ & .11 \\
\hline Interpersonal sensitivity & .02 & .01 & .06 & .07 & .17 & .12 & .24 & .07 \\
\hline Psychoticism & .13 & .16 & .19 & .27 & .20 & .24 & $.47^{* * *}$ & .23 \\
\hline Paranoid ideation & .02 & -.04 & .05 & .01 & .06 & .06 & $.34^{*}$ & .12 \\
\hline Hostility & .23 & .17 & .12 & .22 & .17 & .17 & $.30 *$ & .22 \\
\hline Phobic anxiety & -.06 & -.00 & -.02 & .05 & .19 & .10 & .18 & -.06 \\
\hline
\end{tabular}

${ }^{*} p<.05, * * p<.01, * * *<.001$. Bolded values indicate significance at the .05 level after Holm-Bonferroni correction. 
group compared to the control group (see Table 3).

\section{Relations Between Parent Characteristics and ASD Behaviors}

For children with ASD, their total aberrant behavior score was significantly and positively correlated with only their mothers' obsessive-compulsive symptoms out of all mother psychological symptoms (Table 4). From $A B C$ 's subscales, the significant correlations were between mother obsessive-compulsive symptoms and child stereotypic behavior and inappropriate speech, and maternal depression symptoms and child inappropriate speech (Table 4).
When put into a hierarchical linear regression, mothers' obsessive-compulsive symptoms continued to predict children's aberrant behaviors beyond child age, mother age, and mother education ( $6=.27, p<.05$ ) (Table $5)$. It explained an additional $7 \%$ of variance in child aberrant behaviors beyond these variables $\left(\Delta R^{2}=.067\right.$, $p<.05)$. Mother obsessive-compulsive scores continued to predict child stereotypic behaviors $\left(B=.26, \Delta R^{2}=\right.$ $.062, p<.05)$ and inappropriate speech $\left(B=.26, \Delta R^{2}\right.$ $=.064, p<.05$ ) beyond these demographic variables. Mother depression scores also continued to predict inappropriate speech beyond these variables $(B=.28$, $\left.\Delta R^{2}=.076, p<.05\right)$.

Table 4. Correlations between parent psychological symptoms and aberrant behaviors in ASD group

\begin{tabular}{|c|c|c|c|c|c|c|}
\hline $\begin{array}{l}\text { Child } \\
\text { Aberrant } \\
\text { Behaviors } \\
\text { Parent } \\
\text { Symptoms }\end{array}$ & $\begin{array}{l}\text { Irritability, } \\
\text { agitation, crying }\end{array}$ & $\begin{array}{l}\text { Lethargy and } \\
\text { social withdrawal }\end{array}$ & $\begin{array}{l}\text { Stereotypic } \\
\text { behavior }\end{array}$ & $\begin{array}{l}\text { Hyperactivity, } \\
\text { noncompliance }\end{array}$ & $\begin{array}{l}\text { Inappropriate } \\
\text { speech }\end{array}$ & $\begin{array}{l}\text { Total Aberrant } \\
\text { Behavior Score }\end{array}$ \\
\hline Somatization & .00 & -.03 & .06 & -.04 & .08 & .00 \\
\hline Anxiety & .10 & -.02 & .07 & .04 & .13 & .06 \\
\hline Obsessive-compulsive & .22 & .23 & $.26^{*}$ & .11 & $.26^{*}$ & $.27^{*}$ \\
\hline Depression & .18 & .21 & .17 & .12 & $.27^{*}$ & .23 \\
\hline Interpersonal sensitivity & .13 & .08 & .04 & .06 & .16 & .11 \\
\hline Psychoticism & .08 & .01 & .12 & -.04 & .14 & .07 \\
\hline Paranoid ideation & .07 & .11 & .07 & .04 & .22 & .11 \\
\hline Hostility & .10 & .08 & .12 & .14 & .13 & .12 \\
\hline Phobic anxiety & .11 & .08 & .14 & .01 & .22 & .13 \\
\hline
\end{tabular}

$* p<.05$

Table 5. Hierarchical Regression Analysis for the Predictors of Child Aberrant Behaviors in the ASD group

\begin{tabular}{|l|c|c|c|}
\hline Variable & B & SE (b) & \\
\hline Step 1 & & 4.01 & .07 \\
\hline Mother obsessive-compulsive symptoms & 8.76 & & $.27^{* * *}$ \\
\hline Step 2 & & 1.03 & .12 \\
\hline Child age & .83 & .64 & -.22 \\
\hline Mother age & -.93 & 3.12 & -.01 \\
\hline Mother education & -.17 & 4.12 & $.27^{*}$ \\
\hline Mother obsessive-compulsive symptoms & 8.68 & & \\
\hline
\end{tabular}

$* * * p<.001, * * p<.01 ; * p<.05$

\section{DISCUSSION}

This study investigated the relationship between different child behavior problems and parent psychological problems in children with ASD and their mothers, and typically developing (TD) children and their mothers. The main findings of our study indicated that psychological problems in parents and problematic behaviors in children were higher in the ASD group compared to the TD group. In the ASD group, maternal obsessive-compulsive symptoms predicted children's stereotypical behaviors and inappropriate speech, and maternal depression predicted child inappropriate speech.

Social functioning problems, pragmatic problems, OCD phenomenon, and/or early language or reading problems have previously been reported to be higher in the families of ASD children (7). Going beyond 
reporting the characteristics of parents or relatives of ASD, the present study related these characteristics with the behaviors of children with ASD. In the present study, children with ASD were found to display more problem behaviors than TD children, and mothers of children with ASD had significantly more psychological symptoms than mothers of TD children. Mothers of children with ASD experienced significantly more problems in their pregnancies than mothers of TD children (Table 1), which aligns with factors during pregnancy and early development influencing altered development in ASD. Though the mothers of both groups of children had comparable education levels, significantly fewer mothers of children with ASD were employed (Table 1), presumably to stay home and take care of their child. Mothers' symptoms were associated to a greater extent with the behavioral problems in the ASD group compared to the control group. When a child with ASD displays aggressive or anxious-depressed behaviors besides the core ASD symptoms, these are associated with higher depressive or obsessive-compulsive problems in mothers. In the TD group, the only significant relation was between mother psychoticism and child delinquency, and no relations between obsessive-compulsive symptoms in mothers and child behavior problems emerged.

Comorbidity of ASD and OCD is widely reported in the literature. A large study with 7922 young individuals on the co-occurrence of OCD and ASD has reported that $25 \%$ of individuals with OCD also had a diagnosis of ASD [21]. The risk of later diagnosis of OCD is 2-fold higher in individuals with ASD and the risk of a later diagnosis of OCD is nearly 4-fold higher in individuals with ASD compared to their TD peers (22). The obsessivecompulsive traits have been shown to be higher in fathers of ASD probands than the fathers of TD controls (23). In our study, we investigated the relationship with maternal obsessive-compulsive symptoms and the children's behaviors in the ASD group. When ASD core symptoms were investigated beyond the broader child behavior problems, mothers' obsessive-compulsive symptoms predicted children's aberrant ASD-related behaviors in the ASD group. This prediction held beyond demographic variables as child age, maternal age, and maternal education. Mothers' obsessivecompulsive symptoms especially predicted stereotypic behaviors and inappropriate speech, where the latter was also significantly predicted by mother depression symptoms. Findings are in support of our prediction that parent obsessive-compulsiveness would be related to children's stereotypic behaviors. Stereotypic behaviors were characterized in this checklist with items such as "repetitive hand, body or hear movements", "waves, shakes extremities repeatedly", "rocks body back and forth", and "stereotyped, repetitive movements" (15). It makes sense that such repetitive actions would be related to obsessive-compulsive symptoms of parents, which are measured with items as "having to check and double-check what you do" and "having to repeat the same actions such as touching, counting, washing" (19). This study adds to the previous finding that obsessivecompulsive traits in parents are associated with the insistence on sameness in children with ASD by showing that obsessive-compulsive traits in parents not only predict insistence on sameness, but also stereotypic behaviors and inappropriate speech in children with ASD (8).

Present results showed that inappropriate speech in children with ASD was significantly predicted beyond demographic variables by mother obsessive-compulsive symptoms and mother depression symptoms. The inappropriate speech was characterized by the following items: "talks excessively", "talks to self loudly", "repeats a word or phrase over and over", and "repetitive speech" (15). It makes sense that obsessive-compulsive traits in parents would predict the latter two items, which suggest repetition or stereotypy and resemble in nature the items for stereotypic behaviors listed above, which were also significantly predicted by parent obsessivecompulsive symptoms. Parent depression symptoms may be more related to the former two items in this list of talking excessively and talking to self loudly. Since this was a cross-sectional study, data cannot be interpreted in a causal direction. Either parents who are depressed may have no patience or energy to correct the excessive or loud talking of their children, or children's excessive or loud talking may precipitate parent depression. When we consider the high prevalence of depression in the mothers of children with ASD, the need for interventions targeting children with ASD and their families becomes apparent (24). Additionally, it should be noted that ABC is not an autism-specific scale and can be used with other neurodevelopmental disorders such as intellectual disability. In this study, ABC was used in the ASD group whose diagnosis was confirmed with semi-structured CARS interviews.

There are certain limitations of our study. The first limitation is that its cross-sectional nature prevents causality explanations and does not inform about whether parental or child variables cause the other. The directionality of the findings can be clarified with 
future longitudinal studies. The second limitation is about evaluating mothers of children with SCL-90R, which is a self-report questionnaire and not a clinical interview. Another limitation is the sample size of the study. We believe that the findings of our study provide valuable contributions to the field, but nonetheless, it is important to repeat our results in larger samples and preferably with longitudinal designs.

Obsessive-compulsive symptoms in parents may be a risk factor for ASD, as it seems to be the parental trait most strongly correlated with child ASD symptoms. Therefore, investigating genes commonly implicated in OCD and ASD can help narrow the search for the genetic fingerprint for these disorders and point to specific gene groups that can help accelerate investigations on the genetics of ASD.

Conflict of Interest: The authors declare that they have no conflict of interest for this study.

\section{REFERENCES}

[1] American Psychiatric Association. Diagnostic and statistical manual of mental disorders. 5th ed. American Psychiatric Pub; 2013.

[2] Tick B, Bolton P, Happé F, Rutter M, Rijsdijk F. Heritability of autism spectrum disorders: a meta-analysis of twin studies. J Child Psychol Psychiatry 2016;57(5):585-95. doi: 10.1111/ jcpp.12499.

[3] Mitra I, Lavillaureix A, Yeh E, Traglia M, Tsang K, Bearden CE, Rauen KA, Weiss LA. reverse pathway genetic approach identifies epistasis in autism spectrum disorders. PLoS Genet. 2017;13(1):e1006516. doi: 10.1371/journal.pgen.1006516.

[4] Chahrour M, O'Roak BJ, Santini E, Samaco RC, Kleiman RJ, Manzini MC. Current perspectives in autism spectrum disorder: From genes to therapy. J Neurosci. 2016;36(45):11402-11410. doi: 10.1523/JNEUROSCI.2335-16.2016.

[5] Losh M, Adolphs R, Poe MD, Couture S, Penn D, Baranek GT, Piven J. Neuropsychological profile of autism and the broad autism phenotype. Arch Gen Psychiatry 2009;66(5):518-526. doi: 10.1001/archgenpsychiatry.2009.34.

[6] Piven J, Palmer P, Jacobi D, Childress D, Arndt S. Broader autism phenotype: Evidence from a family history study of multipleincidence autism families. Am J Psychiatry 1997;154(2):185190. doi: 10.1176/ajp.154.2.185

[7] Piven J, Palmer P. Psychiatric disorder and the broad autism phenotype: Evidence from a family study of multiple-incidence autism families. Am J Psychiatry 1999;156(4):557-563. doi: 10.1176/ajp.156.4.557.

[8] Abramson RK, Ravan SA, Wright HH, Wieduwilt K, Wolpert CM, Donnelly SA, Pericak-Vance MA, Cuccaro ML. The relationship between restrictive and repetitive behaviors in individuals with autism and obsessive compulsive symptoms in parents. Child Psychiatry Hum Dev. 2005;36(2):155-165. doi: 10.1007/ s10578.005.2973-7.

[9] Hollander E, King A, Delaney K, Smith CJ, Silverman JM. Obsessive-compulsive behaviors in parents of multiplex autism families. Psychiatry Res. 2003;117(1):11-16. doi: 10.1016/ s0165-1781(02)00304-9.

[10] Kucuk O, Ulaş G, Yaylacı F, Miral S. Broad autism phenotype. Current Approaches in Psychiatry 2018;10(2);228-248. doi:10.18863/pgy.358099 [Turkish].

[11] Guo W, Samuels JF, Wang Y, Cao H, Ritter M, Nestadt $\mathrm{PS}$, et al. Polygenic risk score and heritability estimates reveals a genetic relationship between ASD and OCD. Eur Neuropsychopharmacol. 2017;27(7):657-666. doi: 10.1016/j. euroneuro.2017.03.011.

[12] Evans DW, Uljarević M, Lusk LG, Loth E, Frazier T. Development of two dimensional measures of restricted and repetitive behavior in parents and children. J Am Acad Child Adolesc Psychiatry 2017;56(1):51-58. doi: 10.1016/j.jaac.2016.10.014.

[13] Achenbach, Thomas $M$, and Edelbrock C. Child behavior checklist. Burlington (Vt). 1991;7:371-392.

[14] Erol N, Arslan BL, Akçakın M. Sergeant J. The adaptation and standardization of the Child Behavior Checklist among 6-18 year-old Turkish children. Eunethydis: European Approaches to Hyperkinetic Disorder 1995;97-113.

[15] Aman MG, Singh NN, Turbott SH. Reliability of the Aberrant Behavior Checklist and the effect of variations in instructions. Am J Ment Defic. 1987;92(2):237-240.

[16] Karabekiroglu K, Aman MG. Validity of the aberrant behavior checklist in a clinical sample of toddlers. Child Psychiatry Hum Dev. 2009;40(1):99-110. doi: 10.1007/s10578.008.0108-7.

[17] Schopler E, Reichler RJ, DeVellis RF, Daly K. Toward objective classification of childhood autism: Childhood Autism Rating Scale (CARS). J Autism Dev Disord. 1980 ;10(1):91-103. doi: 10.1007/BF02408436

[18] Sucuoglu B, Oktem F, Akkok F, Gokler B. A study on the scales used in the evaluation of autistic children. 3P Dergisi-3P Journal 1996;4(2):116-121 [Turkish].

[19] Derogatis LR, Lipman RS, Covi L. SCL-90: An outpatient psychiatric rating scale-preliminary report. Psychopharmacol Bull. 1973;9(1):13-28.

[20] Dag, I. (1991). Symptom Checklist (SCL-90-R): A reliability and validity study for university students. Turkish Psychiatry Journal 1991; 2(1):5-12 [Turkish].

[21] Martin AF, Jassi A, Cullen AE, Broadbent M, Downs J, Krebs G. Co-occurring obsessive-compulsive disorder and autism spectrum disorder in young people: prevalence, clinical characteristics and outcomes. Eur Child Adolesc Psychiatry 2020. doi: $10.1007 / \mathrm{s} 00787.020 .01478-8$.

[22] Meier SM, Petersen L, Schendel DE, Mattheisen M, Mortensen PB, Mors O. Obsessive-compulsive disorder and autism spectrum disorders: Longitudinal and offspring risk. PLoS One 2015;10(11):e0141703. doi: 10.1371/journal.pone.0141703.

[23] Kano $Y$, Ohta $M$, Nagai $Y$, Pauls DL, Leckman JF. Obsessivecompulsive symptoms in parents of Tourette syndrome probands and autism spectrum disorder probands. Psychiatry Clin Neurosci. 2004;58(4):348-352. doi: 10.1111/j.14401819.2004.01266.x.

[24] Ingersoll B, Meyer K, Becker MW. Increased rates of depressed mood in mothers of children with ASD associated with the presence of the broader autism phenotype. Autism Res. 2011;4(2):143-148. doi: 10.1002/aur.170. 